\title{
Author Spotlight: Yejoo Jeon
}

\section{Yejoo Jeon $^{1}$}

Accepted: 8 March 2021 / Published online: 30 March 2021

(c) The Author(s), under exclusive licence to Springer Science+Business Media, LLC, part of Springer Nature 2021

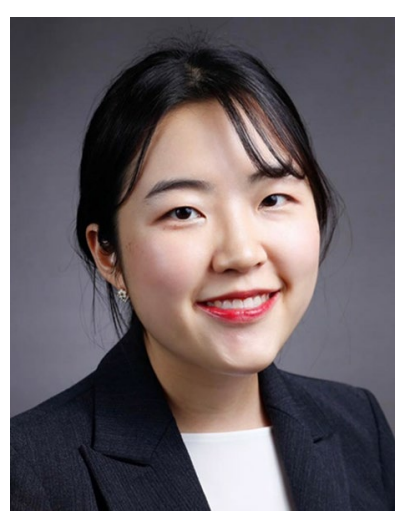

Yejoo (Christina) Jeon is an internal medicine resident at the University of California, Los Angeles. She received her medical education at the Yale School of Medicine and has served as a Fulbright Research Scholar. Her current research interest is the intersection of Non-alcoholic Fatty Liver Disease and Inflammatory Bowel Disease. She is looking forward to applying to gastroenterology fellowships this year.

Publisher's Note Springer Nature remains neutral with regard to jurisdictional claims in published maps and institutional affiliations.
Yejoo Jeon

YejooJeon@mednet.ucla.edu

1 Department of Internal Medicine, University of California, Los Angeles (UCLA), Los Angeles, USA 